\title{
Antecedents of Tourists Behavioural Intentions, Perspectives of Expectations Confirmation Model: A Study of Select Tourism Cites in South-East Nigeria
}

\author{
Nwatu Basil Chibuike ${ }^{1, *}$, Nwaizugbo Ireneus Chukwudi², Ganiyu Rahim Ajao $^{3}$ \\ ${ }^{1}$ Department of Marketing, Enugu State University of Science and Technology, Enugu, Nigeria \\ ${ }^{2}$ Department of Marketing, Nnamdi Azikiwe University, Awka, Nigeria \\ ${ }^{3}$ Department of Business Administration, University of Lagos, Lagos, Nigeria \\ Email address: \\ chibuike.nwatu@esut.edu.ng (N. B. Chibuike), ic.nwaizugbo@unizik.edu.ng (N. I. Chukwudi), arahim@unilag.edu.ng (G. Rahim Ajao) \\ ${ }^{*}$ Corresponding author
}

\section{To cite this article:}

Nwatu Basil Chibuike, Nwaizugbo Ireneus Chukwudi, Ganiyu Rahim Ajao. Antecedents of Tourists Behavioural Intentions, Perspectives of Expectations Confirmation Model: A Study of Select Tourism Cites in South-East Nigeria. International Journal of Education, Culture and Society. Vol. 6, No. 5, 2021, pp. 176-189. doi: 10.11648/j.ijecs.20210605.13

Received: July 26, 2021; Accepted: August 12, 2021; Published: October 12, 2021

\begin{abstract}
Tourism has expanded dramatically in Nigeria over the last six decades, becoming one of the largest and fastestgrowing sectors of the Nigerian like in the global economy. The World Travel and Tourism index ranked Nigeria $129^{\text {th }}$ out of 140 countries and Nigeria's ranking is well below average rankings for sub-Saharan Africa. This study was motivated by the need to explore the antecedents of tourists' behavioural intentions from the perspectives of the expectations confirmation model. The study extended the model by adding perceived trust to original components. Several studies have been conducted from the perspective of this model in tourism in many countries but none in Nigeria. The study was based on a sample 400 tourists selected from the five states in the South East geopolitical zone of Nigeria out of which 317 respondents returned valid questionnaire. The study population was infinite hence respondents were those seen at the various tourist sites and who agreed to fill the questionnaire. The analysis utilized partial least squares structural equations modelling (PLS-SEM) with the aid of WarpPLS version 7.0. All the hypothesised relationships are statistically significant (Table 6). The $95 \%$ confidence intervals straddle no zero in-between for all the hypotheses. The Effect sizes in our analysis range from as high as 0.409 for Confirmation which is the highest to 0.209 for PP and 0.149 for CE. Conf. and PT have 0.094 and 0.084 respectively hence all the IVs in our analysis fall within acceptable range from medium to high effect sizes and are all considered relevant in our model. Implications of the study were also discussed and recommendations for further study were also made.
\end{abstract}

Keywords: Antecedent, Tourist, Behavioural Intention, Confirmation Model, Tourism, Southeast Nigeria

\section{Introduction}

The World Travel and Tourism Council (WTTC) noted that tourism sector earned a total of $\$ 18,077.4$ which represents $4.5 \%$ of total Nigeria's gross domestic product (GDP) in the year 2019 [1], the report equally, contend that tourism GDP grew at the rate of $2.2 \%$ while the overall economy grew at the rate $2.1 \%$ in 2019 . In terms of jobs creation, tourism accounts for three thousand three hundred and fifty four $(3,354)$ jobs which represents $4.7 \%$ of total employment. On the international impact or foreign exchange earnings, tourism earned $\$ 2.392 .9$ which represents $4.1 \%$ of total exports for Nigeria in 2019. Thus the tourism sector is very strategic to economy of Nigeria like in many other countries.

The World Economic Forum-Travel and Tourism Competitiveness Report (TTCR), shows that Sub-Saharan Africa outpaces the global average for growth in tourism receipts and arrivals, with the island nation of Mauritius (54th) outscoring last year's top performer South Africa (61st) to rank as top scorer in the region (WEF-TTCR, 2019). The report laments that due to historically lower levels of economic development, the region continues to face difficulties in health and hygiene, overall infrastructure and 
the effective selling of cultural and business travel. In the face of this, however, Sub-Saharan Africa shows great untapped potential for natural tourism, which can be better utilized with more development and investment. Some of the region's greatest improvements came from areas where it traditionally has trailed, including ICT readiness, international openness and price competitiveness. Lesotho (128th to 124th) had the greatest growth in score since 2017; however, it was the average growth in the economies of Western Africa that generated the most sub regional improvement. Nigeria is ranked $129^{\text {th }}$ out of 140 countries. It is comprised of four sub-indices, 14 pillars and 90 individual indicators, distributed among the different pillars. Nigeria's ranking for the 14 pillars are below average rankings for subSaharan Africa.

Tourism cites in Southeast Nigeria include Agulu Lake Resort, Ogbunike Cave and Igbokwu Musuem (Anambra State) and in Enugu State are the yearly Mmanwu Festival, Ezeagu Cave and Warm Springs and the Ethnographic/Cultural Museum of National Unity Enugu. In Abia State there are the Arochukwu Slave route, Museum of Colonial History Aba, and National War Museum Umuahia, Azumini Blue River. In Imo State there is also a National Museum, Oguta Lake and Mbari Cultural \& Arts Centre; while in Ebonyi State there are the Okposi Salt Lake, and Afikpo Sand Beach among others.

Several models have been used in consumer satisfaction studies. These models include the disconfirmation of expectations model, perceived performance model, rational expectations model, expectations-artefact model, attribution model, cognitive dissonance model, comparison level model, contrast model, and the Kano model. There are also other country specific models of satisfaction like the American Customer Satisfaction Index (ASCI) model contains six constructs which are customer expectation, perceived value, perceived quality, customer satisfaction, complaint behaviour, and customer loyalty. It was developed in 1994 by random sampling of 250 of the 200 firms' customers. Of all these the expectations, confirmation model appears to be the dominant model for studying customer satisfaction. Interestingly, marketing and tourism literature have been dominated by an expectations, confirmation model (ECM), which maintains that customer satisfaction is the result of contrast between expectation and service performance. As such, expectation affects satisfaction indirectly through disconfirmation with actual service performance, whether it is positive disconfirmation (performance exceeds expectation) or negative disconfirmation (expectation exceeds performance) [2, 3]. An increasing number of researchers have expressed their concerns on its applicability in typical continuous service consumptions (such as tourism) featuring aggregated, cumulative customer satisfaction, where the consumer (tourist) can learn from the ongoing travel experience, and their prior expectation can be evolving during the trip $[4,5]$. The study of Mohajerani and Miremadi was on customer satisfaction in hotel industry while Aziz et $a l$. focused on tourist's satisfaction. All these studies are alien and are on customer satisfaction [6, 7]. Yunduk et al. study on behavioural intentions in sporting events in South Korea; and to the knowledge of the researcher no study has been conducted to validate expectations and confirmation model (ECM) dimensions of expectation, perceptions, and confirmation/disconfirmation with perceived trust on tourists' behavioural intentions in Southeast Nigeria. This study is set to explore the antecedents of tourists' behavioural intentions from the perspectives of expectations confirmation model (ECM) based on the selected tourists in Southeast Nigeria. The study is also set out to extend the ECM by adding the dimension of perceived trust from service quality (SERVQUAL) which is also a known model in customer satisfaction; and is considered a critical factor in customers' behavioural intentions [8].

\section{Literature Review}

\subsection{Concept of Tourism}

Tourism is travel for pleasure or for business; also theory and practice of touring, the business of attracting, accommodating, and entertaining tourists, and the business of operating tours. The World Tourism Organisation (WTO) defines tourism more generally, in terms which go beyond the common perception of tourism as being limited to holiday activities only, as people travelling to and staying in places outside their usual environment for not more than one consecutive year for leisure and not less than 24 hours, for business and other purposes [9]. Also the Oxford Advanced Learners Dictionary of Current English defines tourism as: the business activity connected with providing accommodation, services, and entertainment for people who are visiting a place for pleasure. The definition of tourism by the UNWTO is more encompassing as it recognises tourism as comprising a broad range of activities, and goes beyond the common perception of limiting tourism only to holiday activity [9]. Tourism involves lodging in hotels and visiting places of interest like the Ogbunike Cave, a UNESCO Heritage cite in Anambra State which is one of the states within the scope of this present study. These definitions no doubt relates to the demand side of tourism as they relate mainly to the products and services offered. There is also the supply of tourism and in this context tourism is also seen as an industry in which we are referring to firms, hotels, recreation parks and heritages among others that provide leisure. Industries are competitors and group of business enterprises that are engaged in a common type of economic activity. Economic activities are categorized according to some classification system, such as the United Nations' International Standard Classification of Economic activities [9]. It is important to note however that tourism cannot be identified in terms of a particular good or service. Example is when a customer buys a bottle of soft drink at a local store to quench his/her taste that cannot be categorized as tourism. But when a visitor to Ogbunike Cave for holiday/leisure such a soft drink in the same store activity becomes 'tourism' [9]. 
Tourism transaction in this regard can be seen in three dimensions: the consumer, the product and the supplier.

Tourism is an activity which human beings have undertaken for a very long time in history. In recent time, tourism has become an important social and economic phenomenon. UNWTO reports that the impact of tourism is increasingly being felt at the individual level and through its impacts on society [9]. Tourism can be domestic (within the traveller's own country) or international, international tourism has both incoming and outgoing implications on a country's balance of payments. In this regard tourism transactions and expenditures as evidenced in literature are multiple and includes: family tourist expenditure, visits to friends/relatives; travel for business and professional purposes; government sponsored trips; and social incentive or price tourism. In light of this several expenditures are included in tourism and they are: accommodation; food and drinks; transport; recreation, culture and sporting activities; shopping among others.

Some scholars viewed tourism as a complex phenomenon that is extremely difficult to describe clearly, pointing out that any model of tourism must "capture" the composition or components of the tourism system, as well as the key processes and outcomes that occur within tourism [10]. These processes and outcomes they said include the very essence of tourism, the travel experience, and the supporting means by which tourism is made possible. They identified the three components of tourism as: the tourist, who is at the very heart of tourism; Natural Resources and Environment, which is a fundamental dimension of the model, the very basis of which tourism is the natural resources and environment component; and the built environment is included in culture of the residents of the host region. Goeldner and Ritchie listed the operating sectors of the tourism industry or what is perceived as tourism. First and foremost, the transportation sector, comprising airlines, bus companies, and so on, tends to typify the movement of people and travel [10]. The accommodation/hotel sector, which includes many well-known brands such as Best Western, and so on, is highly visible to the public. And the food services sector which also contains a broad spectrum of brands and logos that have become part of everyday life in many communities. This food sector includes the sustainable food as well as the informal sector food vendors dotting the landscape of Nigeria.

\subsection{Tourism in Nigeria and South East Nigeria}

There are conflicting historical reports on European visits and exploration of Nigeria. While some history reports that the Portuguese first landed in Benin about 1452, Alamai et al. stated that the country (Nigeria) had her first international tourists in 1472, when Portuguese merchants visited Lagos, apparently in search of trade. Whatever is the case tourism in Nigeria has continued to grow appreciably [11]. This was such that in 1962, the Government established the Nigerian Tourist Association (NTA) and charged it with the responsibility of promoting domestic and international tourism in the country [12]. In 1976, NTA was dissolved and the Nigerian Tourism Board (NTB) established in its place. The development of the sub-sector was boosted in 1992, when the Ministry of Trade and Industry was created, and the NTB became a Corporation following the establishment of the Nigerian Tourism Development Corporation (NTDC) as a Federal Government Corporation under the Ministry of Culture, Tourism, and National Development. The Corporation is responsible for the planning, supervision, development and marketing of tourism in Nigeria. According to the Corporation, tourism is a central pillar of economic growth and diversification in any country (NTDC, 2020). Accordingly, the major functions of NTDC include among others: to encourage people living in Nigeria to take their holiday therein and people from abroad to visit Nigeria and also to encourage the provision and improvement of tourism amenities and facilities in Nigeria.

To give further boost to tourism in Nigeria, the National Travel Bureau (NTB), was established by Decree No. 81 of 1992, as a tour company responsible for tour services and operations within and outside Nigeria. The Bureau acts as the commercial arm of NTDC and is responsible for conducting guided tours/excursions, Bus Rental Services, Travel Consultancy and Tour Guide Services. The vision for the establishment of the National Tour Bureau according to information from the NTDC website was that of the Nigerian Tourist Association. It was done at a time to ensure that guided tours, sightseeing and package holidays are in place. According to the NTDC information, the NTB is to strengthen private tour companies which are unable to purchase tourist bases.

The imperativeness of tourism lies in its great potentials for generating foreign exchange. The World Travel and Tourism Council allude that tourism earned $\$ 18,077.4$ representing $4.5 \%$ of the total Nigeria's revenue the year 2019. The report adds that while tourism GDP grew at $2.2 \%$ the overall economy grew at $2.1 \%$ in that same year. In terms of jobs, WTTC reports that tourism account for 3,354 Thousand jobs which represents $4.7 \%$ of total employment for Nigeria in same period. In terms of international visitor impact or foreign exchange earnings tourism account for $\$ 2.392 .9$ Million representing $4.1 \%$ of the total exports for Nigeria in 2019.

On the global scene, tourism accounts for $10.3 \%$ of World GDP and account for 330 Million jobs. WTTC reports that tourism accounts for 1 in every 10 jobs adding that while global economy grew by $2.5 \%$ Travel and Tourism grew significantly at the rate of $3.5 \%$. One in four net new jobs were created by Travel and Tourism over the last 5 years. Four countries: Niger (10\%), Benin (5\%), Cameroon (5\%), United States $(5 \%)$ and China (4\%) share $28 \%$ of inbound arrivals in tourism, while the rest of the World account for $72 \%$. In terms of departures, United States $(17 \%)$, Ghana (16\%), Saudi Arabia (12\%), United Kingdom (9\%) and South Africa (5\%) share $59 \%$ of the tourism outbound, while the rest of the World share $41 \%$ of outbound departures. In terms of sector characteristics, leisure spending account for $55 \%$ 
while business spending represent $45 \%$. In same vein, while domestic spending account for $80 \%$, international spending account for just $20 \%$ of tourism spending in 2019 [1]. This study scope is the South East Nigeria hence we present top 10 Cites in the region.

\subsection{Theoretical Review and Research Framework}

The confirmation/disconfirmation of expectation model (ECM) was developed structurally in a series of two papers written by Oliver [13]. It is a cognitive theory that seeks to describe post-purchase or post-adoption satisfaction as a function of expectations, perceived performance, and disconfirmation of beliefs. In other words, it shows how customer satisfaction is affected by the summation of product performance and customer's expectation level. The model submits that in a situation where the performance that a customer perceives is adjudged to be higher than the expectations obtained, satisfaction will rise. This is known as positive disconfirmation. However, when a perceived performance is lesser than the customers' level of expectation, the result will be a decrease satisfaction hence, negative disconfirmation $[13,14]$. Therefore, satisfaction is a function of the disparity between performance and expectations, and satisfaction is indicated by the disconfirmation model; it forecasts that as expectations rise, satisfaction will decline. The ECM besides studies in job satisfaction literature, disconfirmation of expectation model has enjoyed widespread support from scholars in other fields, and it has been generally used in appraising and measuring satisfaction with diverse products, like the hospitality sector [3]. However, the disconfirmation of expectations model has been scarcely used in the field of Internet marketing, sustainability marketing, health marketing, and social marketing. ECM posits that satisfaction is determined by interplay of prior expectations and perception of delivery. As such, there are many applications in research and practice that employ an ECM [15]. The descriptive power allows independent investigations manipulating either of the components and a format to examine just why clients are satisfied (or not) with a particular product or service [15].

The dimensions of the ECM are: expectation, performance, (dis)confirmation and customer satisfaction. In this study the final dependent variable is replaced by behavioural intention. Also, because our study is based on tourists' behavioural intentions, the variable of trust was added as an independent variable that directly impinge on customer behavioural intentions. Tourism is a service and perceived trust is very crucial in shaping customers/tourists' behavioural intentions. Hence the research model/framework is as shown in figure 1.

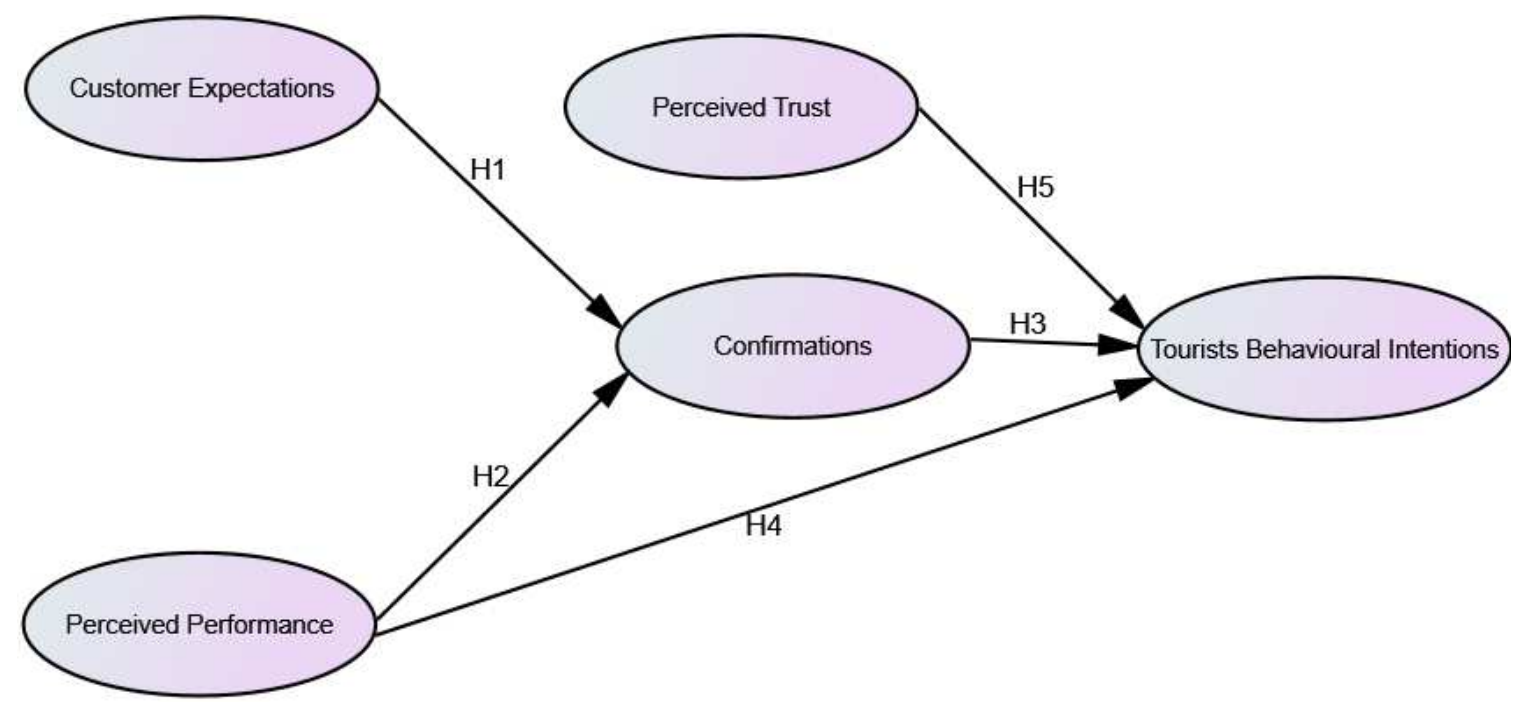

Figure 1. The Research conceptual model.

\subsubsection{Customer Expectations (CE)}

The ACSI model defines customer expectations as the level of quality that customers expect to receive and as such serves as the benchmark that is adjusted or updated in accordance with a customer's more recent purchase and consumption experience or what has been communicated to him or her about the product or service. CEs sum up a customer's prior consumption experience with a firm's products or services as well as marketing communication and word-of-mouth information [16]. A wide range of factors create customer expectations. A customer's previous experiences, the communication of an organisation with its customers, advertisements, service recovery, promises, informal recommendations, formal recommendations, price to be paid, personal needs, corporate image and salespeople all influence the formation of customer expectations [17, 18]. CEs are regarded as necessary in predicting a firm's ability to provide future performance and as such should have a positive influence on confirmation/disconfirmation. With the above we formulate the following hypothesis:

$\mathrm{Ha}_{1}$ : There is a significant positive relationship between tourists' expectations and the confirmations/disconfirmations of tourism organisations in South East Nigeria. 


\subsubsection{Perceived Performance (PP)}

Performance, in the context of urban tourism, refers to a tourists' cognitive appraisal of the superiority of tourismrelated service/product in fulfilling their needs during a city trip [19]. Both the marketing and tourism literatures suggest that perceived performance is one of the strongest predictors (or even the sole determinant) of customer satisfaction [20, 21]. This positive effect has been established through substantial empirical studies in various tourism sectors including accommodation, retailing, tour operator and casino $[19,22]$. Our study is on tourist behavioural intentions hence it is believed that perceived performance positively relate to confirmation/disconfirmation. Based on the above, we formulated the following hypotheses:

$\mathrm{Ha}_{2}$ : Tourists' perceived performance of tourism organisations would significantly and positively impact the tourists' confirmation/disconfirmation in the South East region of Nigeria.

$\mathrm{Ha}_{4}$ : Tourism organisations perceived performance would significantly and positively impact tourists' behavioural intentions in South East Nigeria.

\subsubsection{Confirmation-Disconfirmation}

Confirmation is defined as the objective judgment of client on the difference in experience of pre-expectation and actual experience [2]. Customer satisfaction is affected by expectation and disconfirmation [23]. Literarily, disconfirmation indicates the gap between expectations and perceived performance. Bhattacherjee argued that the confirmation is positively related to satisfaction with information system use because it implies realization of the expected benefits of information system use, whereas disconfirmation (perceived performance lagging expectation) indicates failure to achieve expectation. Our study is on tourism and it is expected that (dis)confirmation positively relate to tourists behavioural intentions [24].

Based on the above the hypothesis is formulated:

$\mathrm{Ha}_{3}$ : Tourists' confirmation/disconfirmations has a significant and positive impact on tourists' behavioural intentions in the South East region of Nigeria.

\subsubsection{Perceived Trust}

A customer's perceived trust can lead to confirmation/disconfirmation among tourists. Trust is proposed as an important antecedent of loyalty [25, 26], because it helps initially to attract new customers and later to retain existing ones [27]. Consumers' perceived trust can also influence their overall satisfaction [25], because trust is an important factor in consumer outcome evaluation and can equally contribute to positive behavioural intention toward tourism. In this era of online transaction or pervasive e-marketing, perceived trust can create value by providing relational benefits that are derived from interaction, thus reducing the uncertainty of the exchange. Accordingly, perceived trust was added to the ECM in this study and is expected to have a positive impact on tourists' behavioural intentions. Based on the above, the following hypothesis is formulated:
Based on this the following proposition is made:

$\mathrm{Ha}_{5}$ : There is a significant and positive effect between perceived trust and tourists' behavioural intentions in South East Nigeria.

\subsubsection{Behavioural Intentions}

Behavioural intention has long been an important dimension of consumer, marketing and tourism studies. The concept can be depicted as a tourists' intention to revisit based on past memorable experiences at a destination and to engage in word-of-mouth [28]. Most researchers have long regarded behavioural intention as one of the most reliable sources of information regarding potential tourists [29]. Lee and Han ascertained behavioural intention can decrease negative recognition and perceived risk of destination, which indicates behavioural intention should be considered when evaluating the success tourism [30]. Our study is on antecedents of tourists behavioural intentions form the perspective of the ECM hence behavioural intention (figure 1) is the last dependent variable and it is expected that it will be positively affected by performance, confirmation/disconfirmation and perceived trust.

\subsection{Empirical Review}

Several researchers have conducted empirical studies in both marketing and tourism on customers' behavioural intentions, this study also looked at some of these empirical works. Yunduk et al. conducted a study on the determinants of behavioural intentions in the context of sport tourism with the aim of sustaining sporting destinations. They examined structural relationships between event quality, tourist satisfaction, place attachment, and behavioural intentions with emphasis on the mediating effects of tourist satisfaction and place attachment on relations between event quality and behavioural intentions in the context of a small-scale recurring sporting event. Responses obtained from 350 attendees were collected and analysed. Results showed positive impacts of (a) event quality, tourist satisfaction and place attachment on behavioural intentions, (b) event quality and tourist satisfaction on place attachment, and (c) event quality on tourist satisfaction, and demonstrated (d) tourist satisfaction and place attachment partially mediate relationships between event quality and behavioural intentions and that (e) place attachment partially mediates the relationship between tourist satisfaction and behavioural intentions [8]. In a recent study looked at the antecedents of tourists' behavioural intentions at sporting events based on a case of South Korea. They noted that mega-sporting events can bring diverse benefits to the hosting areas, such as job creation and image improvement. The problem they investigated was that only a handful of studies have explored the antecedents of destination image which plays a crucial role in eliciting certain tourist behaviours and personal involvement [31]. To fill this gap, study from the World Masters Championships Gwangju in 2019 evaluated the relationships among personal involvement, destination image, place attachment, and behavioural intentions in the context of sporting event tourism to provide destination managers useful information for sustainable sports tourism 
development. They gathered information from 374 international tourists at the FINA (Fédération Internationale de NatationInternational Swimming Federation) in South Korea. They used structural equation modelling along with maximum likelihood estimation to examine the predicted relationships. The findings showed positive impacts of (a) personal involvement on destination image, (b) destination image on place attachment, and (c) place attachment on behavioural intentions. Furthermore, (d) place attachment dictated the relationship between destination image and behavioural intentions. The findings confirm the significant role personal involvement plays in the improvement of a destination's image. To ensure sustainable sports tourism, destination managers are advised to pay close attention to research findings on destination image in the development of their plans.

The import of this to the present study is that the study used an extended variant of the ECM on which the present study is based but in a different extension.

Terblanche studied was on an application of the American customer satisfaction index (ACSI) in the South African motor vehicle industry. The problem that informed his study was that of management's major challenges in employing a model that is appropriate to explain and predict customer retention for a particular company or brand. This study investigated the reliability of the ACSI for South Africa and reports on the empirical findings in respect of the relationships between various dimensions in the ACSI model as applied in the South African motor vehicle industry. The focal point of the study was the South African motor vehicle industry as a whole as well as two individual motor vehicle brands. The strengths of various relationships, for instance, the relationship between customer satisfaction and customer loyalty and the relationship between customer expectations and perceived value were studied. The findings of the study are supportive of the views of authors that endorse a positive relationship between satisfaction and loyalty. At the same time the findings are in conflict with the views of various authors who state that customer satisfaction cannot be a sole predictor of customer loyalty. Different items might also improve such measurement [32]. The implication of this study is that it was based on ACSI which is one of the models for investigating customer satisfaction and loyalty hence this review is very relevant to this present study.

Alamai et al. study was a desk analysis of tourism and the economy of Nigeria: a synthesis of its contributions to GDP from 2005-2016 [11]. They noted that for many emerging economies and several less developed countries (LDCs) such as Burkina Faso, Gambia, and Nigeria tourism is an export earner as it has proved to be a strong and resilient economic activity that contributes to the economic recovery of nations through generation of billions of dollars in income while also stimulating job creation for destinations across the globe. Their paper is a theoretical review of the direct, indirect and induced impact of tourism to the economic growth of Nigeria over a period of 16 years. They recommend among other things the entrenchment of sound tourism development master plan capable of rejuvenating the potentials in the economic blueprint of the country and ensuring sustainable tourism development participation even in the face of difficulties and uncertainties.

\section{Methodology}

\subsection{Research Design}

This study adopted quantitative research design which is considered the mainstay of research in marketing and consumer behaviour research. Quantitative research places major emphasis on using standard questions and predetermined response options in designing questionnaire and or surveys administered to large sample of respondents [33]. Quantitative research methods are more directly related to descriptive and causal research designs. Hence this research adopted majorly the descriptive and causal design. Accordingly the main objective of the study as stated is to explore the causal effects of the antecedents of ECM on tourists' behavioural intentions.

\subsection{Population and Sample}

Population of study refers to all units of analysis that are of important to a researcher and on which the researcher may collect data [34]. The population of this study comprises all adults in South East who can visit tourist sites or museums for recreation, relaxation or for site seeing. This study was on based sample of 400 tourists/respondents selected equally among the five South East states covered by the study. The sampling method adopted is the quota sample which allows a researcher to include respondents from all the segments or strata of the population without minding the probability of inclusion. Hence we made people from diverse gender, educational background, income among others were included among the respondents. The researcher(s) employed the assistance of some tourist centre staff to administer the research instrument to the respondents which happened in three months.

\subsection{Sources of Data and Instrument Design}

Data for this study came from two sources: secondary sources and primary sources. Secondary sources of data came from journals, textbooks, and other published works. Questionnaire was the instrument used for primary data collection. Five constructs were used in this study: customers' expectations (CE), perceived performance (PP), confirmation (Conf.), perceived trust (PT) and tourists' behavioural intentions (TBI). In terms of measurement, CE and PP were measured with 5 items each, Conf. was measured with 3 items while PT and TBI were measured 4 items each. All the items were measured on a five point Likert scale of strong agree, agree, undecided, disagree and strongly disagree.

\subsection{Statistical Technique}

Tables and percentages were used to present some aspects 
of the data while descriptive statistics were used to check the behaviour of data. Partial least squares structural equations modelling (PLS-SEM) was used in estimation and validation of the hypotheses. There are some reasons for this. First is that PLS-SEM has been employed and used extensively by previous researchers and authors [35, 36] and has been established as an appropriate tool for analysis and estimation just like the covariance-based (CB-SEM) model [33]. Next is that PLS-SEM as a non-parametric component of SEM makes less demand on data compared to the CB-SEM. Nevertheless, the PLS-SEM software used for the analysis is WarpPLS version 7.0, the advantage of which is that it brings together "the precision of CB-SEM algorithms under common factor model assumptions with the nonparametric characteristics of classic PLS algorithms" [37]. Also the sample size for this study is over 300 and this is large enough as further justified the use of SEM in analysis.

\section{Data Analysis}

\subsection{Data Presentation and Descriptive Analysis}

The captive sample for this study is 317 respondents. This means that out of the sample of 400,317 returned valid and usable copies of the questionnaire. This represents 79.25 per cent response which is considered quite high for a study of this nature. Four socio-demographic variables were used in the study and the responses are presented in Table 1.

Table 1. Socio-demographic characteristics of respondents.

\begin{tabular}{|c|c|c|c|c|}
\hline \multicolumn{2}{|c|}{ Socioeconomic variables } & \multirow{2}{*}{$\begin{array}{l}\text { Frequency } \\
175\end{array}$} & \multirow{2}{*}{$\begin{array}{l}\text { Percent } \\
55.2\end{array}$} & \multirow{2}{*}{$\begin{array}{l}\text { Mean/mode } \\
\text { Male }\end{array}$} \\
\hline & Male & & & \\
\hline Gender: & Female & 142 & 44.8 & \\
\hline \multirow{3}{*}{ Age: } & $18-35$ years & 67 & 21.1 & \\
\hline & $36-55$ years & 187 & 59.0 & 44 years \\
\hline & 56 years and above & 63 & 19.9 & \\
\hline \multirow{3}{*}{ Occupation: } & Student/apprentice & 56 & 17.7 & \\
\hline & Self-employed & 166 & 52.4 & Self-employed \\
\hline & Unemployed & 31 & 9.8 & \\
\hline \multirow{5}{*}{ Education: } & Primary/secondary & 54 & 17.0 & \\
\hline & Non-formal & 90 & 28.4 & \\
\hline & $\mathrm{NCE} / \mathrm{HND} / \mathrm{BSc}$ & 127 & 40.1 & $\mathrm{NCE} / \mathrm{HND} / \mathrm{BSc}$ \\
\hline & Postgraduate & 46 & 14.5 & \\
\hline & Total & 317 & 100.0 & \\
\hline
\end{tabular}

As shown in Table 1, $175(55.2 \%)$ of the respondents are males while $142(44.8 \%)$ are females. This shows near equal representation in the genders in our sample. Most of the respondents, $187(59.0 \%)$ are within their prime ages of $36-$ 55 years of age, $63(19.9 \%)$ are above 56 years; while 67 $(21.1 \%)$ are within $18-35$ years. The average age of the respondents was found as 44 years which implies that those visiting tourist site in the study area are relatively young and active. In terms of occupation, $56 \quad(17.7 \%)$ are student/apprentice, majority $166(52.4 \%)$ are self-employed, $64(20.2 \%)$ are civil servants while $31 \quad(9.8 \%)$ are unemployed. This means that majority of the respondents are have something doing and can give valid responses. On education, majority of $127(40.1 \%)$ of the respondents have $\mathrm{NCE} / \mathrm{HND} /$ first degrees, while $90(28.4 \%)$ have non-formal education, $54(17.0 \%)$ have primary/secondary education, and $46(14.5 \%)$ have postgraduate qualifications. This implies that majority of respondents have reasonable education to give valid responses and to be included in the study. The next are the descriptive statistics.

\subsection{Data Treatment}

Table 2 present the information requested for each of the items used to measure the variables of the study. The next two columns show the minimum and maximum and the highest under maximum is 5 while the least under minimum is 1 . This a confirmation that the variables were measured with five-point scale coded one to five. Those variables with a mean score of 3.0 and above are those that are in agreement with the respondents. Standard deviations measure variability hence with standard deviations from 0.5 and above is high enough to accept the respondent's decision. The skewness value provides an indication of the symmetry of the distribution. Kurtosis on the other hand provides information about the "peakedness" of the distribution. Positive skewness values indicate positive skew (scores clustered to the left at the low values). Negative skewness indicate a clustering of scores at the high end (right-hand side of a graph). Positive kurtosis values indicate that the distribution is rather peaked (clustered in the centre), with long thin tails. Kurtosis values below 0 indicate a distribution that is relatively flat (too many cases in the extremes). With reasonably large samples, skewness will make a substantive difference in the analysis [38]. In Table 2, the skewness and kurtosis values are all negative. This implies that there are more items in the extreme. This problem of distribution was overcome by the fact partial least squares (PLS) structural equations modelling was used in the analysis. One of the advantages of PLS-SEM over other tools of multivariate statistical analysis is that it does not require a normally distributed data [39]. Also Tabachinick and Fidell maintained that with reasonably large samples $(200+$ cases $)$ skewness 'will not make substantive difference in the analysis' [40]. 
Table 2. Descriptive Statistics.

\begin{tabular}{|c|c|c|c|c|c|c|c|c|c|}
\hline \multirow{2}{*}{ Items } & \multirow{2}{*}{$\begin{array}{l}\text { N } \\
\text { Statistic }\end{array}$} & \multirow{2}{*}{$\begin{array}{l}\text { Minimum } \\
\text { Statistic } \\
\end{array}$} & \multirow{2}{*}{$\begin{array}{l}\text { Maximum } \\
\text { Statistic }\end{array}$} & \multirow{2}{*}{$\begin{array}{l}\text { Mean } \\
\text { Statistic }\end{array}$} & \multirow{2}{*}{$\begin{array}{l}\text { Std. Deviation } \\
\text { Statistic } \\
\end{array}$} & \multirow{2}{*}{$\begin{array}{l}\text { Skewness } \\
\text { Statistic }\end{array}$} & \multicolumn{3}{|c|}{ Kurtosis } \\
\hline & & & & & & & Std. Error & Statistic & Std. Error \\
\hline ce1 & 317 & 1.00 & 5.00 & 2.839 & 1.020 & -0.465 & 0.137 & -0.902 & 0.273 \\
\hline ce2 & 317 & 1.00 & 5.00 & 3.142 & 0.768 & -0.711 & 0.137 & 0.299 & 0.273 \\
\hline ce3 & 317 & 1.00 & 5.00 & 3.069 & 0.894 & -0.725 & 0.137 & -0.220 & 0.273 \\
\hline ce4 & 317 & 1.00 & 5.00 & 3.013 & 0.968 & -0.763 & 0.137 & -0.357 & 0.273 \\
\hline ce 5 & 317 & 1.00 & 5.00 & 2.956 & 0.927 & -0.680 & 0.137 & -0.305 & 0.273 \\
\hline pt1 & 317 & 1.00 & 5.00 & 2.672 & 1.064 & -0.282 & 0.137 & -1.144 & 0.273 \\
\hline pt3 & 317 & 1.00 & 5.00 & 2.940 & 0.921 & -0.566 & 0.137 & -0.488 & 0.273 \\
\hline pt4 & 317 & 1.00 & 5.00 & 3.032 & 0.920 & -0.724 & 0.137 & -0.275 & 0.273 \\
\hline pp1 & 317 & 1.00 & 5.00 & 2.871 & 1.025 & -0.484 & 0.137 & -0.912 & 0.273 \\
\hline pp2 & 317 & 1.00 & 5.00 & 3.013 & 0.961 & -0.692 & 0.137 & -0.484 & 0.273 \\
\hline pp3 & 317 & 1.00 & 5.00 & 2.940 & 0.958 & -0.554 & 0.137 & -0.652 & 0.273 \\
\hline pp4 & 317 & 1.00 & 5.00 & 2.934 & 1.003 & -0.511 & 0.137 & -0.871 & 0.273 \\
\hline Conf1 & 317 & 1.00 & 5.00 & 2.899 & 1.045 & -0.635 & 0.137 & -0.766 & 0.273 \\
\hline tbil & 317 & 1.00 & 5.00 & 2.861 & 1.061 & -0.551 & 0.137 & -0.919 & 0.273 \\
\hline tbi2 & 317 & 1.00 & 5.00 & 2.991 & 0.946 & -0.703 & 0.137 & -0.375 & 0.273 \\
\hline tbi3 & 317 & 1.00 & 5.00 & 2.924 & 0.958 & -0.651 & 0.137 & -0.460 & 0.273 \\
\hline tbi4 & 317 & 1.00 & 5.00 & 3.041 & 1.016 & -0.756 & 0.137 & -0.585 & 0.273 \\
\hline
\end{tabular}

Source: Field Survey, 2020.

\subsection{Common Method Bias}

Researchers are advised to take measures to check Common method bias (CMB) in their researches. CMB stems from a situation where one questionnaire like in this case is used to collect responses on both the independent and the dependent variables. Evidences abound that CMB influences item validities, reliabilities, and the covariance between latent constructs [41]. In view of this, research outcomes where CMB is serious cannot be relied upon as they could be misleading.

Table 3. Correlation among latent constructs.

\begin{tabular}{|c|c|c|c|c|c|}
\hline Latent variables & $\mathbf{C E}$ & PP & Conf. & PT & TBI \\
\hline Customer expectations & 1 & & & & \\
\hline Perceived performance & $0.196^{* *}$ & 1 & & & \\
\hline Confirmation & $0.262^{* *}$ & $0.442^{* *}$ & 1 & & \\
\hline Perceived trust & $0.186^{* *}$ & $0.327^{* *}$ & $0.249^{* *}$ & 1 & \\
\hline Tourists behavioural intentions & $0.188^{* *}$ & $0.392^{* *}$ & $0.454^{* *}$ & $0.288^{* *}$ & 1 \\
\hline
\end{tabular}

Table 4. Full collinearity VIF.

\begin{tabular}{lllll}
\hline Customer expectations & Perceived performance & Confirmation & Perceived trust & Tourists behavioural intentions \\
\hline 1.376 & 1.810 & 2.576 & 1.364 & 2.463 \\
\hline
\end{tabular}

There are qualitative and quantitative measures for addressing issues of CMB. On the qualitative aspect and based on the instructions of Podsakoff et al. [42], the researcher(s) stated in the latter part of the questionnaire that there are no right or wrong answers. Respondents were also assured of anonymity and that their responses are for academic purposes only. Quantitatively and based on the method of Bagozzi et al. [43], the researcher(s) used the Pearson Product Moment Correlation matrix of the latent variables to check for method (Table 3). The correlations among the latent constructs were found to be far below the 0.9 threshold recommended [43]. This shows that method bias is not a problem in our study. The researcher(s) equally used PLS-SEM to test for the hypotheses and Kock [37] recommend using full collinearity VIF to check CMB (Table
4). All the values for the constructs are well below the less than or equal to 3.3 threshold which signifies that common method is not a problem in our study.

\subsection{Measurement Model Validation}

The analysis done in this research utilized the structural equations modelling and it is customary that the measurement model in SEM must be evaluated and validated before assessing the structural model. This involves the estimation of reliability as well as the validity of the study constructs that show the strength of the measures used in the research model. This is to ensure that the measurement model are dependable and reliable as bad measurement model cannot be used to evaluate a structural model since this will produce spurious and unreliable results. 
As shown on Table 4 some of the items have loadings below the 0.6 threshold required but because the items were measures as reflective constructs the bases for inclusion and retention is not just the loading but the level of significance. Table 4 shows that all items have p-values well below the 0.05 margin of error hence no item need to be eliminated. We also look at the normalized item loading and cross loading to check further. Table 6 shows the normalized item loadings and cross loadings and as is shown all items have loadings above the 0.7 which is within the required threshold for items retention and inclusion [44]. No item need to be eliminated. This means that all the items merit further analysis. To further demonstrate that no item need to be eliminated the researcher(s) look at items weights.

Table 5. Combined loadings and cross-loadings.

\begin{tabular}{|c|c|c|c|c|c|c|c|}
\hline Items & $\mathbf{C E}$ & PP & Conf. & PT & TBI & SE & P value \\
\hline ce1 & 0.346 & & & & & 0.053 & $<0.001$ \\
\hline ce2 & 0.495 & & & & & 0.052 & $<0.001$ \\
\hline ce3 & 0.229 & & & & & 0.054 & $<0.001$ \\
\hline ce 5 & 0.339 & & & & & 0.053 & $<0.001$ \\
\hline pp1 & & 0.594 & & & & 0.051 & $<0.001$ \\
\hline pp2 & & 0.453 & & & & 0.052 & $<0.001$ \\
\hline pp4 & & 0.553 & & & & 0.052 & $<0.001$ \\
\hline pp5 & & 0.627 & & & & 0.051 & $<0.001$ \\
\hline Conf1 & & & 0.589 & & & 0.051 & $<0.001$ \\
\hline Conf2 & & & 0.689 & & & 0.051 & $<0.001$ \\
\hline Conf3 & & & 0.589 & & & 0.051 & $<0.001$ \\
\hline pt1 & & & & 0.804 & & 0.05 & $<0.001$ \\
\hline $\mathrm{pt} 2$ & & & & 0.516 & & 0.052 & $<0.001$ \\
\hline pt3 & & & & 0.592 & & 0.051 & $<0.001$ \\
\hline tbil & & & & & 0.473 & 0.052 & $<0.001$ \\
\hline tbi2 & & & & & 0.567 & 0.052 & $<0.001$ \\
\hline tbi3 & & & & & 0.436 & 0.053 & $<0.001$ \\
\hline tbi4 & & & & & 0.439 & 0.053 & $<0.001$ \\
\hline
\end{tabular}

Table 6. Normalized combined loadings and cross-loadings.

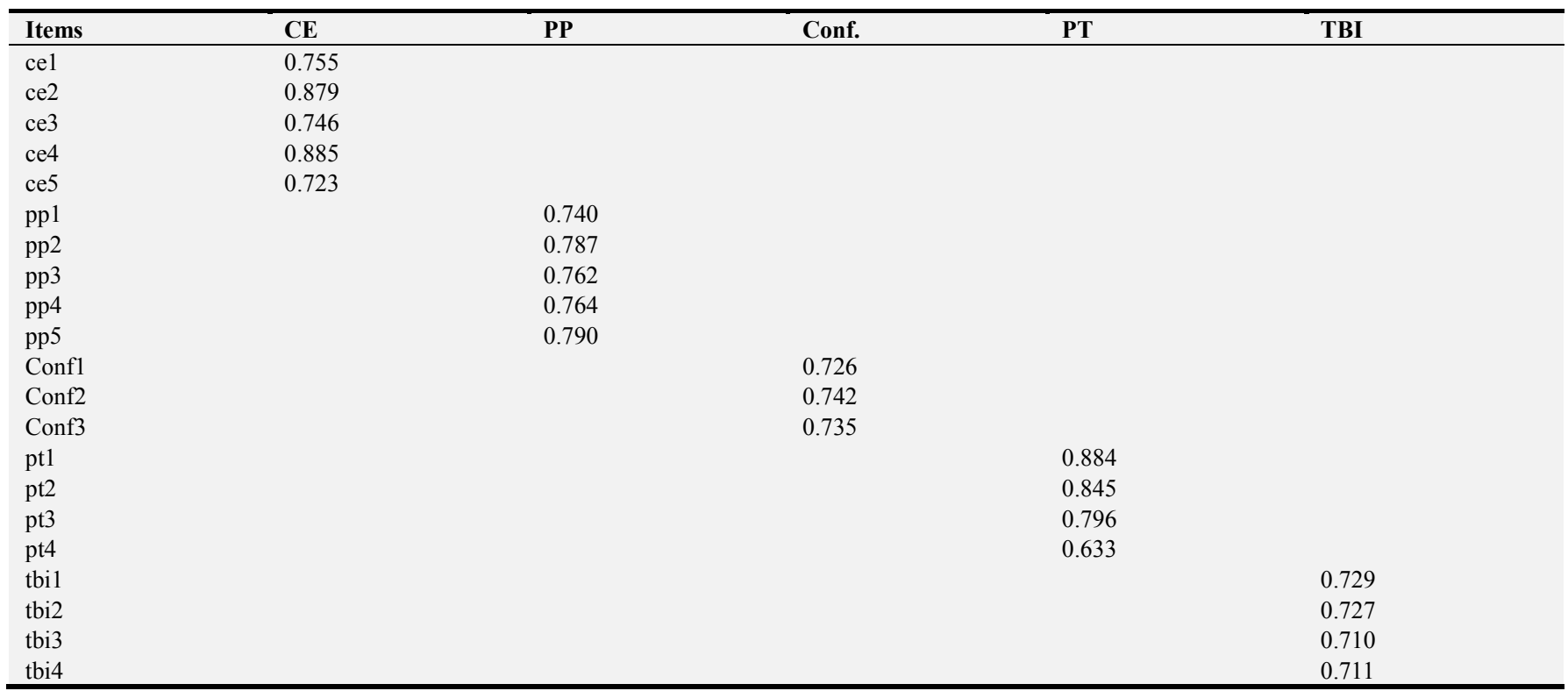

Variance inflation factor (VIF) as shown on Table 7 show that the items are in good stead as they are all below the (VIFs < 2.5) [37]. Indicator weight-loading signs (WLS) are provided for the indicators. A negative WLS (i.e., -1) for an indicator means that the indicator in question is making a negative contribution to the R-squared of its latent variable. Accordingly, it is recommended that all indicator WLS values be positive, for both formative and reflective latent variables [37]. Indicators associated with negative WLS values may be considered for removal. In our study no indicator has a negative sign. Effect sizes (ES) are provided for the indicators of all latent variables. As with the effect sizes for paths, the effect sizes for indicators are calculated as the absolute values of the individual contributions of the corresponding indicators to the R-squared coefficients of the latent variable to which each indicator is associated [37]. The 
values usually recommended are 0.02, 0.15, and 0.35; respectively. It is recommended that all indicator effect sizes be equal to or greater than 0.02 , for both formative and reflective latent variables [37]. Indicators with effect sizes that do not meet this criterion may be considered for removal. In this study all indicators have ES above 0.02 hence none is a candidate for elimination.

The properties of the construct show the Cronbach's Alpha (CA), composite reliability (CR) and the average variance extracted (AVE), as well as items loadings (Table 8). Cronbach's alpha addresses the question of whether the indicators for latent variables display convergent validity and hence display reliability. By convention, the same cutoffs apply: greater or equal to 0.80 for a good scale, 0.70 for an acceptable scale, and 0.60 for a scale for exploratory purposes $[45,46]$. Two of our constructs are below while three are acceptable. AVE reflects the average communality for each latent factor in a model, and should be greater than 0.5. AVE is used as a test of both convergent and divergent validity. Again three of the constructs fall below while two are above. 0.5 , hence our scale has both convergent and divergent validity. Composite reliability measures internal consistency and all our constructs are well above the recommended level of 0.7 , which show adequate and satisfactory consistency.

Table 7. Indicator weights, variance inflation and effect sizes.

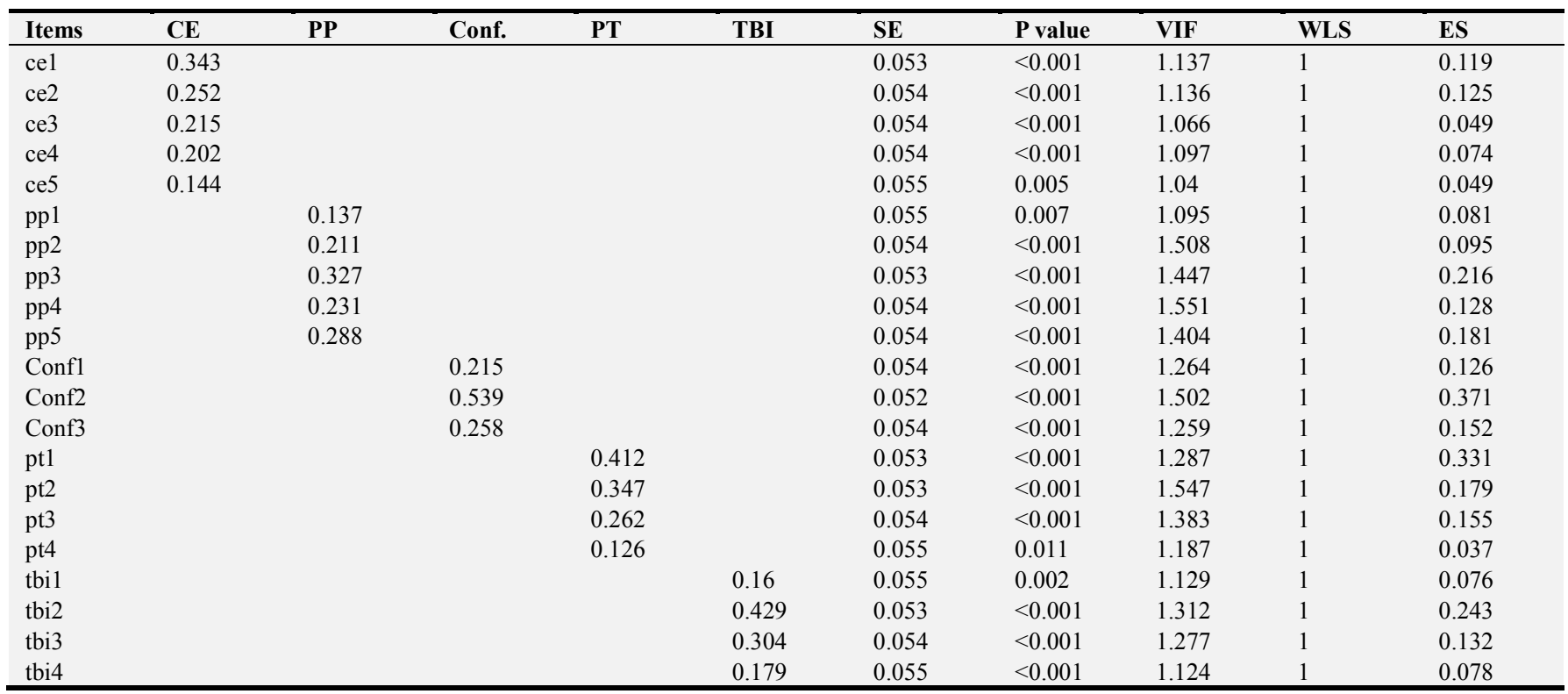

Table 8. Discriminant validity (Fornell Larcker criterion) and reliability.

\begin{tabular}{|c|c|c|c|c|c|c|c|c|}
\hline & $\mathbf{C E}$ & PP & Conf. & PT & TBI & AVE & $\mathbf{C A}$ & $\mathbf{C R}$ \\
\hline Customer expectations & 0.556 & & & & & 0.310 & 0.434 & 0.685 \\
\hline Perceived performance & 0.175 & 0.696 & & & & 0.484 & 0.722 & 0.819 \\
\hline Confirmation & 0.263 & 0.435 & 0.768 & & & 0.590 & 0.648 & 0.811 \\
\hline Toruists' behavioural intentions & 0.176 & 0.38 & 0.442 & 0.267 & 0.653 & 0.426 & 0.537 & 0.742 \\
\hline
\end{tabular}

Table 9. HTMT ratios (good if $<0.90$, best if $<0.85$ ).

\begin{tabular}{lllll}
\hline & CE & PP & Conf. & PT \\
\hline Customer expectations & & & & \\
Perceived performance & 0.407 & & & \\
Confirmation & 0.506 & 0.643 & 0.378 & 0.766 \\
Perceived trust & 0.423 & 0.480 & 0.635 & 0.469 \\
Tourists behavioural intentions & 0.500 & & \\
\hline
\end{tabular}

Table 10. Model fit summary indices.

\begin{tabular}{llll}
\hline Model fit & PLS-SEM value & Threshold & Remark \\
\hline Average path coefficient (APC) $=0.352$, P $<0.001$ & 0.352 & 0.001 & 0.25 \\
$\mathrm{R}^{2}$ (Coefficient of Determination) & 0.532 & $\leq 3.3$ & Good fit \\
Average block VIF (AVIF) & 1.342 & $\leq 3.3$ & Good fit \\
Average full collinearity VIF (AFVIF) & 1.918 & $\leq 0.1$ & $\leq 0.1$ \\
Standardized root mean squared residual (SRMR) & 0.096 & Good fit \\
Standardized mean absolute residual (SMAR) & 0.078 & Good fit & \\
Standardized chi-squared (SChS) & 13.804 & Good fit & Good fit \\
\hline
\end{tabular}


Table 10 also illustrates the discriminant validity of the constructs using the Fornell-Larcker Criterion, with correlation among constructs and the square root of AVE on the diagonal. All values in the diagonal were greater than those in the corresponding rows meaning that all measurement load more highly on their constructs than on other constructs. This implies that tourists' behavioural intentions is reasonably and sufficiently explained by the displayed latent variables' structure (convergent validity) and that this structure includes all unique manifest variables (discriminant validity). Although examination of crossloadings and use of the Fornell-Larcker criterion are accepted methods for assessing the discriminant validity of a PLS model, these methods have shortcomings [47]. We also used the Heterotrait-monotrait (HTMT) ratios (Table 11) to assess discriminant validity. Based on the threshold of Kock [37] all the HTMT ratios fall within acceptable and good range. The p-values are well below the 0.01 margin of error while the $95 \%$ confidence intervals straddle no zero in between. This is a further confirmation that our data has discriminant validity hence we assess the structural model. In addition to measurement model validation, model fit and quality indices were equally validated. The $\mathrm{R}^{2}$ coefficient is one of the most widely quality indices in validating the PLSSEM. The model with all the indicators produced $\mathrm{R}^{2}$ values: Conf. $=0.23$ and $\mathrm{TBI}=0.28$; removing the few items with poor loadings initially did not improve the prediction of the model hence all items were retained as already explained. The initial model was run on PLSRegression but we adjusted the algorithm to PLS-Factor which enhanced prediction significantly to Conf. $=0.44$ and TBI $=0.59$ (Figure 2), hence the PLS-Factor is relied and reported in this research. All the $\mathrm{R}^{2}$ values were well above the threshold Table in 5c. The standardized Chi Square has a value of 13.804 with p-value less than 0.01 while the standardized root mean squared residual (SRMR) and standardized absolute mean residual (SMAR) were all within required threshold. This means that our model has a good fit. All the model quality and fit indices met the established threshold and the criteria [37].

\subsection{Structural Model Validation}

The main objective of this study is to explore tourists' behavioural intentions from the perspective of ECM. In validating the structural model as is normal with PLS-SEM, we rely on $\mathrm{R}^{2}$ which reflects the percentage of variation in the dependent variable (DV) that is accounted for by the independent variables (IVs) hypothesized to affect it; and the $\mathrm{Q}^{2}$ which shows the predictive relevance of our model and the constructs (Table 11). Also used in assessing the model are path coefficients that make up the inner model measure of the effect of IVs on the DV, the effect sizes, p-values, and tvalues. Table 6 contain these items and their values.

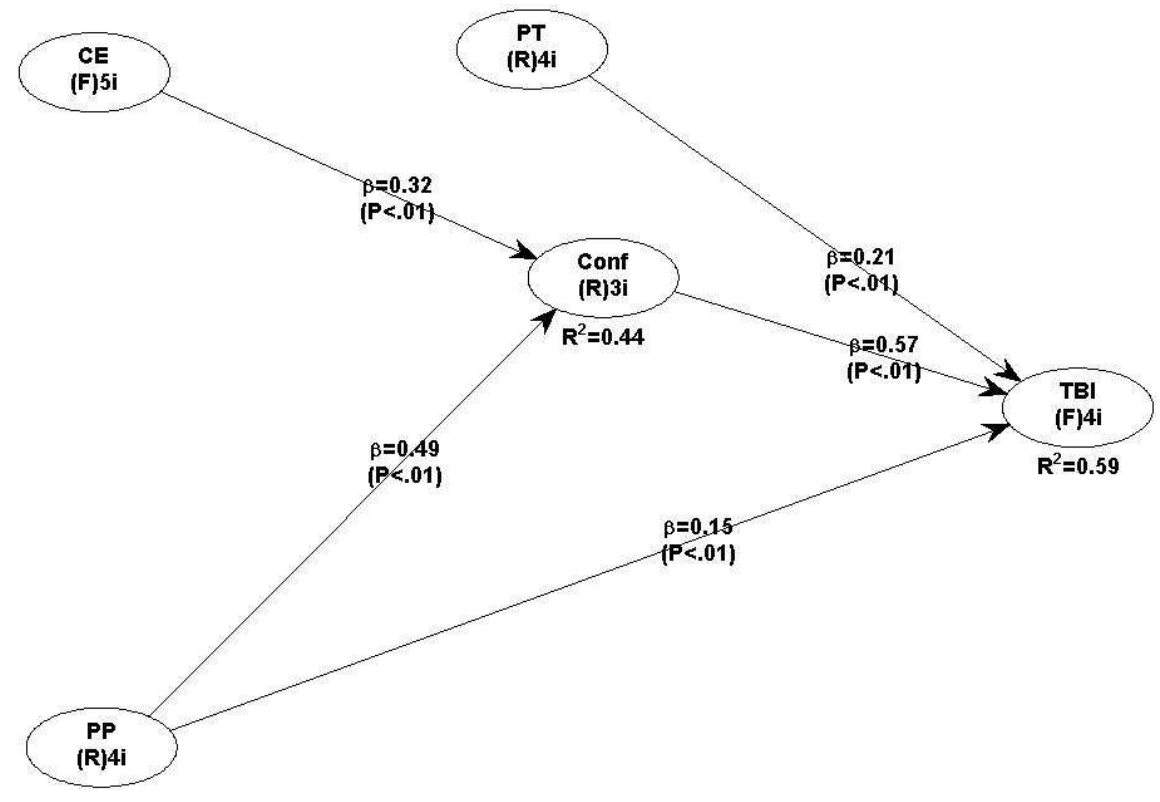

Figure 2. The research structural model.

Table 11. Assessing the structural model.

\begin{tabular}{|c|c|c|c|c|c|c|c|}
\hline Paths & Coefficients & SE & t-values & p-values & Decision & 95\% Confidence interval & Effect Sizes \\
\hline CE -> Conf. & 0.321 & 0.053 & 5.851 & $<0.01$ & Supported & $0.208,0.418$ & 0.149 \\
\hline PP -> Conf. & 0.494 & 0.052 & 10.051 & $<0.01$ & Supported & $0.420,0.623$ & 0.289 \\
\hline PP -> TBI & 0.154 & 0.055 & 4.319 & $<0.01$ & Supported & $0.128,0.340$ & 0.084 \\
\hline PT $->$ TBI & 0.212 & 0.054 & 3.198 & $<0.01$ & Supported & $0.417,0.620$ & 0.094 \\
\hline Conf. -> TBI & 0.566 & 0.052 & 9.993 & $<0.01$ & Supported & $0.068,0.282$ & 0.409 \\
\hline
\end{tabular}

Notes: $\mathrm{SE}=$ standard error. 
All the hypothesised relationships are statistically significant (Table 11). The 95\% confidence intervals straddle no zero in-between for all the hypotheses. The part CE -> Conf. $(\beta=0.321$; $\mathrm{t}$-value $=5.851, \rho=<0.001)$. This result validates $\mathrm{Ha}_{1}$ that there is a significant positive relationship between customers' expectations and the confirmations of tourism organisations in South East Nigeria. The part PP -> Conf. $(\beta=0.494$; $t$-value $=10.051 ; \rho=<0.01)$ and based on this, $\mathrm{Ha}_{2}$ : Tourists' perceived performance of tourism organisations would significantly and positively impact the tourists' confirmation/disconfirmation in the South East region of Nigeria is validated and accepted. The part Conf. -> TBI has $(\beta=0.566$; $\mathrm{t}$-value $=9.993 ; \rho=<0.01)$ and based on this, $\mathrm{Ha}_{3}$ : Tourists' confirmation/disconfirmations has a significant and positive impact on tourists' behavioural intentions in the South East region of Nigeria is accepted and validated. The part PP $->$ TBI has $(\beta=0.154$; $\mathrm{t}$-value $=4.319$; $\rho=<0.01)$ and based on this, based on this $\mathrm{Ha}_{4}$ : Tourism organisations perceived performance would significantly and positively impact tourists' behavioural intentions in South East Nigeria is validated and accepted. The effect from PT -> TBI $(\beta=0.212 ; \mathrm{t}$-value $=3.198 ; \rho=<0.01)$ and with this $\mathrm{Ha}_{5}$ : There is a significant and positive effect between perceived trust and tourists' behavioural intentions in South East Nigeria is validated and accepted.

The effect sizes are the absolute values of the individual contributions of the corresponding latent IVs to the Rsquared coefficients of the DV. With this we ascertain whether the effects indicated by path coefficients are small, medium, or large. The values usually recommended are 0.02 , 0.15 , and 0.35 ; respectively. Values below 0.02 suggest effects that are too weak to be considered relevant, even when the corresponding $\mathrm{P}$ values are statistically significant. The Effect sizes in our analysis shown in Table 6 range from as high as 0.409 for Confirmation which is the highest to 0.209 for PP and 0.149 for CE. Conf. and PT have 0.094 and 0.084 respectively hence all the IVs in our analysis fall within acceptable range from medium to high effect sizes and are all considered relevant in our model.

\section{Discussion}

The main trust of this study is to examine tourists' behavioural intentions from the perspective of ECM. It was based on the South East geopolitical zone of Nigeria. The original ECM proposed by Oliver has customer expectations, perceived performance, impacting confirmation while confirmation and perceived performance impact behavioural intentions [2]. In this study the researcher(s) added perceived trust impacting directly on behavioural intentions alongside the perceived performance. This study was based on a sample 317 captive respondents drawn from tourists from the five South East Nigeria. The analysis relied on the partial least squares structural equations modelling with the aid of WarpPLS 7.0 software. Preliminary analysis was done with the statistical package for social science (SPSS) version 25.
The analysis show that the data for the study has indicators for latent variables display discriminant and convergent validity as well as internal/composite reliability.

The ECM since it was propounded has gone through several modifications with additions of more variables mostly borrowed from the several customer satisfaction indices like American Customer Satisfaction index ACSI among others. The present study extended the EC model by adding perceived trust. All the hypothesised relationships are statistically significant (Table 11). Also the 95\% confidence intervals straddle no zero in-between for all the hypotheses. The study found that there is a significant positive relationship between customers' expectations and the confirmations of tourism organisations in South East Nigeria. This is in line with Zeithaml et al. [17]. The author(s) argue that many factor lead to the formation of customers' expectations. The study also found that tourists' perceived performance of tourism organisations would significantly and positively impact the tourists' confirmation in the South East region of Nigeria. This finding is in line with the empirical work of Wong and Dioko; and Boo and Busser that has established positive impact of PP through substantial empirical studies in various tourism sectors $[5,22]$. This study established that Tourists' confirmation has a significant and positive impact on tourists' behavioural intentions in the South East region of Nigeria is accepted and validated. It also showed that there is a significant and positive effect between perceived trust and tourists' behavioural intentions in South East Nigeria is validated and accepted. These results are in line with [8 and 31] that confirmation of price, advert among others impact tourists' behavioural intentions.

Based on the above findings the study concludes that there is a significant positive relationship between customers' expectations and the confirmations of tourism organisations in South East Nigeria. Tourists' perceived performance of tourism organisations would significantly and positively impact the tourists' confirmation/disconfirmation in the South East region of Nigeria. Tourists' confirmation/disconfirmations has a significant and positive impact on tourists' behavioural intentions in the South East region of Nigeria. Tourism organisations perceived performance would significantly and positively impact tourists' behavioural intentions in South East Nigeria. There is a significant and positive effect between perceived trust and tourists' behavioural intentions in South East Nigeria.

Effect sizes (ES) were also established. The ES in this study ranges as high as 0.409 for Confirmation which is the highest to 0.209 for PP and 0.149 for CE. Conf. and PT have 0.094 and 0.084 respectively hence all the IVs in our analysis fall within acceptable range from medium to high effect sizes and are all considered relevant in our model.

\section{Conclusions and Implications}

The findings of this study has a number of implications. 
The study established that tourists' expectations and perceived performance significantly and positively impact tourists' confirmations. The implication of this is that tourist organizations especially in urban tourism like the museums and tourist villages need to offer very attractive services that will continue to appeal to tourists in fulfilling their desires during urban leisure trips. The study also established that perceived performance, trust and confirmation significantly impact behavioural intentions. The implications of this is that tourist organizations take steps to enhance customer's experiences, the communication of an organisation with its customers, advertisements, service recovery, price to be paid, personal needs, corporate image among others all influence the formation of customer expectations and behavioural intentions in the tourism to provide destination managers and tour guides useful information for sustainable tourism development. This study relate to a particular time period hence further studies are recommended in the area of EC model as tourism continues to expand in a growing economy like Nigeria. Also the demographics used are dynamic and further studies are required from time to time more especially as the study did not go into group analysis of how the antecedents impact sub groups.

\section{References}

[1] World Travel and Tourism Council (WTTC, 2020), Nigeria: 2020 Annual research: key highlights. Online.

[2] Oliver RL (1980). A cognitive model of the antecedents and consequences of satisfaction decisions. Journal of Marketing Research, 460-469.

[3] Weber K (1997). The assessment of tourist satisfaction using the expectancy disconfirmation theory: A study of the German travel market in Australia, Pacific Tourism Review, 1 (1): 35-45.

[4] Johnson MD \& C Fornell (1991). A framework for comparing customer satisfaction across individuals and product categories. Journal of Economic Psychology, 12: 267-286.

[5] Wong IA \& LDA Dioko (2013). Understanding the mediated moderating role of customer expectations in the customer satisfaction model: The case of casinos, Tourism Management, $36 ; 188-199$.

[6] Mohajerani P \& A Miremadi (2012). Customer Satisfaction Modeling in Hotel Industry: A Case Study of Kish Island in Iran. International Journal of Marketing Studies, 4 (3); Canadian Centre of Science and Education, www.ccsenet.org/ijms

[7] Aziz NA, Arffin AAM, Omar NA \& SK Yoon (2011). An investigation of international and domestic satisfaction in heritage context: Implications for destination marketing, Journal Pengursan, 33 (11): 61-76.

[8] Yunduk, J, Suk-Kyu K \& Y Jae-Gu (2019). Determinants of Behavioural Intentions in the Context of Sport Tourism with the Aim of Sustaining Sporting Destinations, Sustainability 2019, $\quad 11, \quad 3073 ; \quad$ doi: $10.3390 /$ su11113073 www.mdpi.com/journal/sustainability
[9] United Nations World Tourism Organisation (UNWTO) (1995), Technical Manual: collection of tourism expenditure statistics, World Tourism Organisation online document. Assessed on 2nd October, 2020.

[10] Goeldner, CR \& JRB Ritchie (2012). Tourism: Principles, Practices, and Philosophies, Hoboken, New Jersey: John Wiley \& Sons, Inc.

[11] Alamai MM, Kirfi UH, \& AF Ladi (2018). Tourism and the Economy of Nigeria: A synthesis of its contributions to GDP from 2005-2016. Advances in Social Sciences Research Journal, 5 (11) 256-263.

[12] Munzali D (2011). Tourism development in Nigeria: challenges and prospects for resource diversification. Accessed July 12 (2021) from: https://www.scribd.com/doc/53329130.

[13] Gunning JG (2000). Models of customer satisfaction and service quality as research instruments in construction management. In: Akintoye A, editor. 16th Annual ARCOM Conference, 6-8 September 2000: 1. Glasgow Caledonian University, Association of Researchers in Construction Management. UK: ARCOM; pp. 21-30.

[14] Anderson RE. What is Customer Satisfaction and Why is it Important? 2010. Retrieved from: https://EzineArticles.com/expert/Rose-Elsa Anderson/725116.

[15] Jiang JJ \& G Klein (2009), Expectation-Confirmation Theory: Capitalizing on Descriptive Power, IGI Global, Online Document.

[16] Johnson MD, Gustafson A, Andreassen TW, Lervik L, \& J Cha (2001). The evolution and future of national customer satisfaction index models. Journal of economic Psychology, 22 (2): 217-245.

[17] Zeithaml VA, Parasuraman A \& LL Berry (1990). Delivering Quality Service. New York: The Free Press.

[18] Bebko CP (2000). Service intangibility and its impact on consumer expectations of service quality, Journal of Services Marketing, 14 (1): 9-26.

[19] Song H, Van der Veen R, Li G \& JL Chen (2012). The Hong Kong tourist satisfaction index, Annals of Tourism Research 39 (1): 459-479.

[20] Churchill GA, \& C Surprenant (1982). An investigation into the determinants of customer satisfaction, Journal of Marketing Research 1982, 491-504.

[21] Boo S \& Busser JA (2018). Tourists' hotel event experience and satisfaction: An integrative approach, Journal of Travel \& Tourism Marketing 35 (7), 895-908.

[22] Chen YY, Chien Hsu Y, Chau Tseng H \& Y Chen Lee (2010). Confirmation of Expectations and Satisfaction with the Internet Shopping: The Role of Internet Self efficacy, Computer and Information Science, 3 (3), 14-22.

[23] Bhattacherjee A (2001). Understanding s continuance: an expectation-confirmation model. MIS Quarterly, 25 (3), 351370.

[24] Chiou JS (2004). The antecedents of consumers' loyalty toward Internet service provider. Information \& Management, $41,685-695$.

[25] Reichheld FF (2001). Lead for loyalty. Harvard business review, 76-84. 
[26] Gefen D, Karahanna E \& D Straub (2003). Trust and TAM in online shopping: An integrated model. MIS Quarterly, 27 (1), $51-90$.

[27] Wallin AT \& B Lindestad (1998). Customer loyalty and complex services: The impact of corporate image on quality, customer satisfaction and loyalty for customers with varying degrees of service expertise. Int. J. Serv. Ind. Manag. 1998, 9, 7-23.

[28] Chi CGQ \& H Qu (2008). Examining the structural relationships of destination image, tourist satisfaction and destination loyalty: An integrated approach. Tourism. Management. 2008, 29, 624-636.

[29] Lee DS \& Han HS (2016). A study on the behaviour intention of festival visitors by using theory of planned behaviour: Focusing on moderation effect of perceived risk. Tour. Res., 41, 205-225.

[30] Yunduk JI, Yu A \& K Suk-Kyu (2020). The Antecedents of Tourists' Behavioural Intentions at Sporting Events: The Case of South Korea, Sustainability 2020, 11, 3073; doi: 10.3390/su11113073 www.mdpi.com/journal/sustainability

[31] Terblanche N S (2006): An application of the American customer satisfaction index (ACSI) in the South African motor vehicle industry, South African Journal of Business Management, ISSN 2078-5976, African Online Scientific Information Systems (AOSIS), Cape Town, Vol. 37, Iss. 4, pp. 29-38, http://dx.doi.org/10.4102/sajbm.v37i4.611

[32] Hair JF Bush RP \& DJ Ortinau DJ (2003). Marketing research within a changing information environment. New York: McGraw Hill Publishers. Online Edition.

[33] Okeke, T. C., Olise, M. C. \& Ezeh, G. A. (2014). Research methods in business and management science. 4th edition. Goder ventures Enugu, Nigeria.

[34] Osakwe, C. N (2019), Understanding customer-perceived quality in informal stores, Journal of Services Marketing, 33 (2), 133-147. https://doi.org/10.1108/JSM-05-2018-0162

[35] Ibrahim T. I \& Roni, S. M. (2017), Partial Least Square Approach to Second Order Factor in Behavioural Study of Accounting Information System, SHS Web of Conferences 36, 00032 (2017). Pp. 1-7.

[36] Koch, N. (2020), WarpPLS user manual: version 7.0, ScriptWarp Systems, Laredo, Texas, USA. Online Edition. Downloaded from: www.scriptwarp.com. Assessed on April 12,2020 .
[37] Pallant, J. (2016). SPSS Survival Manual, 5th Edition. Berkshire, England: Open University Press.

[38] Urbach, Nils \& Ahlemann, Frederik (2010). Structural equation modeling in information systems research using partial least squares. Journal of Information Technology and Theory 11 (2): 5-36.

[39] Tabachinick, B. G. \&Fidell, L. S. (2013). Using multivariate statistics. Pearson Educational Inc. One Lake Street, Upper Saddle River, New Jersey.

[40] Mackenzie, S. B. \& Podsakoff, P. M. (2012), Common Method Bias in Marketing: Causes, Mechanisms, and Procedural Remedies, Journal of Retailing 88 (4), 542 555.

[41] Podsakoff, P. M., MacKenzie, S. B., Podsakoff, P. M., Lee, Jeong-Leon, \& Podsakoff, N. P. (2003), Common Method Biases in Behavioral Research: A Critical Review of the Literature and Recommended Remedies," Journal of Applied Psychology, 88 (5), 879-903.

[42] Bagozzi, R. P., Yi, Y., \& Phillips, L. W. (1991). Assessing construct validity in organizational research. Administrative Science Quarterly, 36 (3), 421-458.

[43] Hair, J. F., Black, W. C., Babin, B. J. and Anderson, R. E. (2018), Multivariate Data Analysis, Andover, Hampshire, United Kingdom: Cengage Learning.

[44] Obianefo C. A., Osuafor O. O. \& John N. Ng'ombe (2021). On the Challenges Faced by Female Members of Agricultural Cooperatives in Southeast Nigeria. Journal of Agricultural Extension and Rural Development, 13 (2): 94-106.

[45] Obianefo C. A., Osuafor O. O., Ezeano Caleb I. \& Anumudu O. O. (2020). Mediation effect of adopting good agronomic practices on rice productivity in Anambra State. International Journal of Agricultural and Rural Development, 23 (1): 49134926.

[46] Garson, G. D. (2016). Partial least squares: regression and structural equation models. Glenn Drive Asheboro, NC 27205 USA: Statistical Publishing Associates. E-book.

[47] Hair, J. F., Risher, J. J., Sarstedt, M., \& Ringle, C. M. (2019). When to use and how to report the results of PLS-SEM. European Business Review, 31 (1), 2-24. 